\title{
DETERMINATION OF SERUM ASCITES ALBUMIN GRADIENT IN DOGS
} AFFECTED WITH ASCITES

\author{
KORSAPATI LAKSHMI*1 \& KATTA PADMAJA ${ }^{2}$ \\ ${ }^{1}$ Veterinary Medicine Department, College of Veterinary Science, Korutla, Jagityal district, Telangana, India \\ ${ }^{2}$ Veterinary Medicine Department, College of Veterinary Science, Rajendranagar, Telangana, India
}

\begin{abstract}
Ascites is a term generally defined as fluid accumulation in the peritoneal cavity and one among the major issues noticed in several diseases in dogs. The dogs affected with ascites has abdominal distension due to fluid accumulation, depending on the cause ascitic fluid vary in colours and consistencies. There are various diagnostic procedures which usually examination of an animal both physically and clinically, analysis of biochemical profile like blood urea nitrogen and serum creatinine concentration, total protein triglyceride etc along with estimation of serum ascites albumin gradient (SAAG), radiography, ultrasonography and histopathology. During my present study, 64 dogs were screened and confirmed with various hepatobiliary disorders based upon history, clinical signs, hematological, biochemical parameters estimation and non invasive diagnostic modality like ultrasonography and radiography. Out of 64 dogs diagnosed with hepatobiliary disorders, 32 dogs was diagnosed with ascites. In 32 dogs, ascitic fluid was collected by abdominocentesis and examined for color, transparency and SAAG. The ascitic fluid collected and analyzed which revealed that fluid was transparent and clear with mean value of SAAG as $1.17 \pm 0.10 \mathrm{~g} / \mathrm{dl}$. Estimation of SAAG in the present study is done to determine whether portal hypertension induced ascites as it indirectly measures portal pressure and it.

KEYWORDS: Hepatobiliary Disorders, Dogs, Ascitic Fluid Analysis \& SAAG
\end{abstract}

Received: Mar 13, 2021; Accepted: Apr 03, 2021; Published: Jun 23, 2021; Paper Id.: IJASRJUN202122

\section{INTRODUCTION}

Liver due to its greater functional reserve capacity estimation of function of hepatic organ and its impairment due to conventional means can be possible if there is hepatic dysfunction of $\geq 55 \%$ (Hall and German, 2005). Ascites is defined as fluid accumulation in the peritoneal cavity and "ascites" word can be used interchanged with another terms like excess peritoneal fluid, abdominal effusion, abdominal dropsy, hydroperitoneum. It is usually a general systemic state manifested during various disease conditions in animals. Therefore, it can be concluded that ascites is one of the important clinical manifestation of an underlying disease. Once the cause is properly diagnosed, then only it can be treated accordingly (Krag et al. 2010). Ascitic fluid analysis has a pivotal role in the diagnosing of various hepatobiliary disorders, especially in dogs. Determination of total nucleated count, total protein, specific gravity, SAAG and albumin of ascitic fluid implies that the ascitic fluid is of transudative type. Serum ascites albumin gradient (SAAG) is regarded as a good prognostic parameter for the diagnosis of ascites caused by hepatobiliary disorders (Saravanan et al. 2014). Estimation of SAAG reveals an exact cause of fluid accumulation in the peritoneal cavity viz., ascites. Increased levels of SAAG viz., transudate) confirms portal hypertension in dogs and this might have been resulted by Venous occlusion Cirrhosis and Hepatic failure. Decreased levels of SAAG viz., exudate was a result of malignancy, infection, pancreatitis and nephrotic syndrome in dogs. For the diagnosis of ascites in dogs, generally, the ascitic fluid has to be evaluated. This can happen when it involves the 
abdominal fluid collection to analyze the presence of bleeding, bacteria and makeup of protein. Proteinuria usually causes a condition called hypoproteinemia in dogs resulting in ascites. Various diseases like amyloidosis and glomerulonephritis cause urinary loss of protein. In such cases, urine analysis must be undertaken (Regmi and Shah, 2017).

\section{MATERIALS AND METHODS}

Various dogs presented to campus Veterinary Hospital, Rajendranagar and Veterinary Hospital, Bhoiguda with the history and clinical signs of inappetence, ascites, anorexia, jaundice, lethargy, pale buccal and mucous membranes, vomition, polyuria and polydipsia or other clinical signs indicative of various hepatic and biliary disorders were selected. The ascitic fluid in affected dogs was collected by abdominocentesis (Figure.1) in lateral recumbency by using sterile 22-gauge 1 inch needle percutaneously following aseptic precautions. The ascitic fluid was allowed to flow out of the needle under the influence of gravity (Rudloff, 2005).

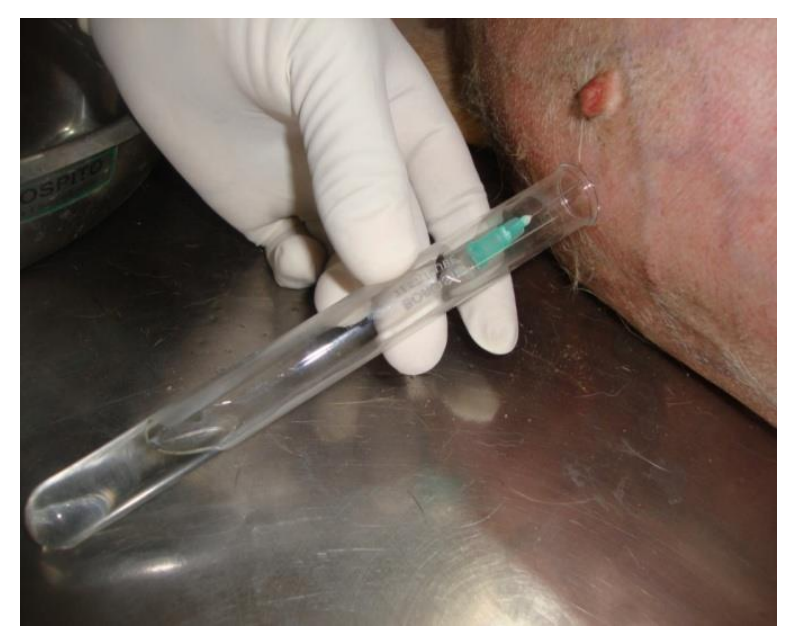

Figure 1: Collection of Ascitic Fluid in a DOG by Abdominocentesis.

The ascitic fluid in dogs was collected by performing aseptic abdominocentesis from the peritoneal cavity of ascitic dogs. The collected ascitic fluid was then evaluated for serum ascites albumin gradient (SAAG). First, we need to calculate the albumin levels from the ascitic fluid and then calculate the serum albumin concentration of the affected dogs. Difference between the albumin level present in the ascitic fluid and the serum albumin concentration should be calculated on the same day, which tells values of SAAG (Saravanan et al., 2014). Serum ascites albumin gradient SAAG = ( albumin concentration in the Serum) - (albumin concentration of ascitic fluid).

\section{RESULTS AND DISCUSSIONS}

During the present study, ascitic fluid was collected from 32 dogs affected with ascites due to hepatobiliary disorders. The ascitic fluid on examination was clear colourless and transparent indicating that the fluid was a pure transudate (Figure.2). (SAAG) Serum ascites albumin gradient from ascitic dogs in the present study was determined and mean value of SAAG was recorded as $1.17 \pm 0.10 \mathrm{gms} / \mathrm{dl}$. 


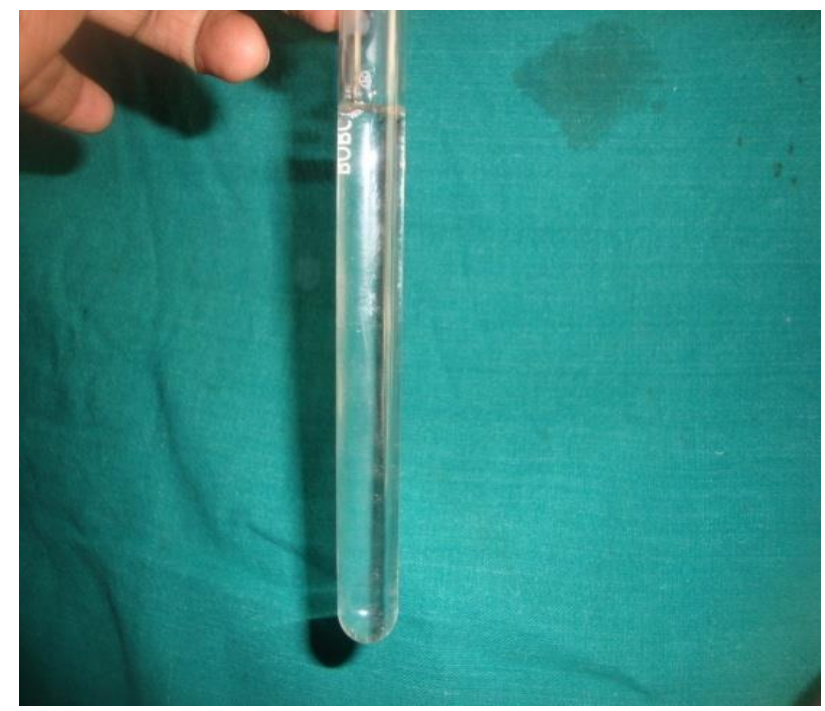

Figure 2: Transudate Type of Ascitic Fluid.

These observations were in accordance with Selgas et al., 2014, who concluded that ascites caused increased weight and this attributes to elevate the chances of the reduced life span of animals. In canine chronic hepatitis, ascites was considered as an indicator which tells about negative prognostic indication which can be followed by a sign of limb edema in dogs. (Raffan et al.,2009). The pathophysiological phenomenon in the development of SAAG attribute to occurrence of Starling's forces among the circulatory system and the peritoneal fluid. When values of SAAG is < 1.1 under normal circumstances due to the presence of oncotic pressure in the serum can be counterbalanced by means of hydrostatic pressure of the serum. During certain diseases like heart failure, or liver cirrhosis this balance between serum oncotic and hydrostatic pressures shall be disturbed causing an increase in the circulatory system hydrostatic pressure. Thus, increased hydrostatic pressure in animals usually lead excess fluid into the peritoneal space to leave the circulation resulting in fluid accumulation viz., ascites. Serum ascites albumen gradient (SAAG) values also shall be increased, as there will be increased excess fluid moving out of circulation, and the albumin levels in serum get concentrating. While, albumin being a larger molecule, its levels don't move easily across the membrane spaces. These observations were in accordance with Bhagat et al. (2013) observed clear, colorless transudate with specific gravity of 1.013 . Removal of ascitic fluid by abdominal paracentesis is seldom necessary when the accumulated fluid is severe enough to impair respiration or renal function or to complicate diagnostic procedures (Webster and Centre, 1995).

Ascitic fluid analysis in animals plays an important role in the diagnosis of hepatic diseases. This analysis shall be useful in either marking the pathological process required for accumulation of fluid in time nor helps advocating necessary diagnostic procedures, arriving in diagnosing various hepatic affections (Papasouliotis and Dewhurst, 2005). Estimation of serum ascites albumen gradient (SAAG) shall reflect the gradient of oncotic pressure occurred between the increased gradient (more than or same as $1.1 \mathrm{~g} / \mathrm{dl}$ ) and vascular bed which was usually being associated with portal pressure increase. While, presence of low oncotic pressure gradient (less than $1.1 \mathrm{~g} / \mathrm{dl}$ ) is attributed to various diseases wherein ascites shall be related to portal hypertension (Tarn and Lapworth, 2010). The present findings corroborated with Vijayakumar et al. (2013) and Saravanan et al. (2014) who documented transudative type of ascites and was depicted by a change in the SAAG levels along with albumin, total cell count, specific gravity and also total protein. Serum ascites albumen gradient (SAAG) determination shall be used as a screening test in dogs affected with ascites due to chronic hepatic disease 
(Bhadesiya et al., 2015). Presence of portal hypertension values of SAAG $>1.1 \mathrm{gm} / \mathrm{dl}$ and portal hypertension results in hepatic cirrhosis (Beg et al., 2001). SAAG indicates 97\% accuracy and helpful in identifying various causes of ascites in dogs (Uddin et al. 2013). Therefore, with the determination of serum ascites albumin gradient (SAAG), the term exudate was named with high serum ascites albumin gradient $(>1.1 \mathrm{~g} / \mathrm{l})$ and transudate was replaced with serum ascites albumin gradient $(<1.1 \mathrm{~g} / 1$ ). Values of serum ascites albumin gradient SAAG (more than $1.1 \mathrm{~g} / \mathrm{l}$ ) revealed $90 \%$ specificity with higher $94 \%$ sensitivity in diagnosing hypertension in portal vasculature than fluid collected from ascitic dogs. Hence, prognostic index concentrations of (SAAG) serum ascites albumin gradient was at $82-97 \%$ in contrast to serum total protein value at $38-85 \%$. In dogs, estimation of total protein level of less than $2.5 \mathrm{~g} / \mathrm{dl}$ at $78 \%$ sensitivity and $50 \%$ specificity (Shanker et al, 2017).

\section{CONCLUSIONS}

Ascitic fluid analysis in dogs was conducted and the mean values of (SAAG) serum ascites albumin gradient was analyzed, observed, can be concluded that the fluid collected from dogs affected with ascites was transudate type. Hence, SAAG has prognostic importance in detecting the cause of ascites in dogs.

\section{REFERENCES}

1. Beg M, Husain S, Ahmad N, \& Akhtar N (2001) Serum/Ascites Albumin Gradient in Differential Diagnosis of Ascites. Journal, Indian Academy of Clinical Medicine, 2(1and 2), 51-54.

2. Bhadesiya CM, Jani RG, Parikh PV, Pandey AM, Rao N, \& Shai A (2015). Hemato biochemistry and imaging study on ascites with hepatic and cardiac involvement in a German shepherd pup. International research journal of chemistry, 11, 14-22.

3. Bhagat L, Sigh J L, Das A K, Arora N and Mamta (2013). Therapeutic management of ascites in canines. Indian Veterinary Journal 90 (1): 26- 29.

4. Hall E. J. and German A. J., 2005 "Laboratory evaluation of hepatic disease," In BSAVA Manual of Canine and Feline Clinical Pathology, E. Villiers and L. Blackwood, Eds. ,184-206, BSAVA, Gloucester, UK, 2nd edition.

5. Krag A, Bendtsen F, Henriksen J, Moller S. 2010. Low cardiac output predicts development of hepatorenal syndrome and survival in patients with cirrhosis and ascites 2(8) 342-348.

6. Raffan E, Mc Callum A, Scase T J, Watson P J 2009. Ascites is a negative prognostic indicator in chronic hepatitis in dogs. Journal of Veterinary Internal Medicine 23: 63- 66.

7. Papasouliotis K, Dewhurst E. Body cavity effusions (2005). In: BSAVA manual of canine and feline clinical pathology, E. Villers and L. Blackwood, Eds, BSAVA, 2nd edition, Gloucester, UK, 340-354.

8. $\quad$ Regmi B and Shah M.K. (2017) Int. J. Appl. Sci. Biotechnol. Vol 5(4): 555-558. DOI: $\quad$ 10.3126/ijasbt.v5i4.18768.

9. Saravanan M, Mondal D B, Sharma K, Kumar M, Vijayakumar H and Sasikala V. 2014. Comprehensive study of hematobiochemical ascitic fluid analysis and ultrasonography in the diagnosis of ascites due to hepatobiliary disorders in dogs. Indian Journal of Animal Sciences.84 (5):503-506.

10. Selgas A G, Bexfield N, Scase T J, Holmes M A, Watson P 2014.Total serum bilirubin as a negative prognostic factor in idiopathic canine chronic hepatitis. Journal of Veterinary Diagnostic investigation 09:1-6.

11. Shanker S, Divya J, Pramod Kumar A, Bijoykumar B 2017. Clinicopathological correlation of serum ascites albumin gradient with ascetic fluid total protein in patients of ascites with portal hypertension attending a tertiary care hospital in eastern Bihar India. International Journal of Advances in Medicine. 4(3):842-846. 
12. Tarn A C and Lapworth R.2010. Biochemical analysis of ascitic fluid: what should We measure. Annals of Clinical Biochemistry. 47, pp: 397-407.

13. Uddin MS, Hoque MI, Islam MB, Uddin MK, Haq I, Mondol G, \& Tariquzzaman M (2013) Serum-ascites albumin gradient in differential diagnosis of ascites. Mymensingh Medical Journal: MMJ, 22(4), 748-54.

14. Webster C R L and Centre 1995. Chronic hepatitis: Therapeutic considerations. In Text book of Kirks current therapy XII Small animal practice by Bonagura J D and Kirk R W, W.B. Saunders Company, Philadelphia, pp:749-756.

15. Diwakar, R. P., et al. "Current Update on Canine Parvovirus in Veterinary Field Aspect." International Journal of Zoology and Research (IJZR) 4.5: 71-82.

16. Dave, Maitry S., and Jatin V. Raval. "The Behaviour of Indian Gray Wolf(Canius Lupus Pallipes) in Captivity at Sakkarbaug Zoo Junagadh, Gujarat, India." International Journal of Environment, Ecology: 2250-0065.

17. Hiremath, Basavaraj, and S. C. Prasannakumar. "Automated Evaluation Of Breast Cancer Detection Using Svm Classifier." International Journal of Computer Science Engineering 5.1: 7-16.

18. Henedi, Adawia. "First molecular identification of adult Heterophyes heterophyes and Heterophyes dispar (digenea: heterophyidae) from Kuwaiti stray cats using its2 sequence." International Journal of Applied and Natural Sciences 8.4: 9-20.

19. Henedi, Adawia. "First molecular identification of adult Heterophyes heterophyes and Heterophyes dispar (digenea: heterophyidae) from Kuwaiti stray cats using its2 sequence." International Journal of Applied and Natural Sciences 8.4: 9-20.

20. Shamin, M. K. "Morphological and Structural Study of Friction Stir Welded Thin Aa6061-T6 Sheets." International Journal of Mechanical Engineering 6.5: 19-24. 
